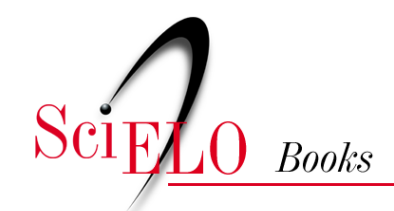

\title{
Porto do Açu, entre as forças de conservação e modernidade
}

\author{
Wedson Felipe Cabral Pacheco
}

\section{SciELO Books / SciELO Livros / SciELO Libros}

PACHECO, W.F.C. Porto do Açu, entre as forças de conservação e modernidade. In: MARAFON, G.J., and RIBEIRO, M.A. orgs. Revisitando o território fluminense, VI [online]. Rio de Janeiro: EDUERJ, 2017, pp. 275-290. ISBN: 978-85-7511-457-5.

https://doi.org/10.7476/9788575114575.0014.

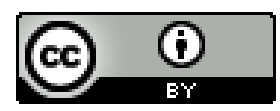

All the contents of this work, except where otherwise noted, is licensed under a Creative Commons Attribution 4.0 International license.

Todo o conteúdo deste trabalho, exceto quando houver ressalva, é publicado sob a licença Creative Commons Atribição 4.0.

Todo el contenido de esta obra, excepto donde se indique lo contrario, está bajo licencia de la licencia $\underline{\text { Creative Commons }}$ $\underline{\text { Reconocimento } 4.0 .}$. 


\section{Porto do Açu, entre as forças de conservação e modernidade}

Wedson Felipe Cabral Pacheco ${ }^{1}$

\section{Introdução}

0 estado do Rio de Janeiro é composto por 92 municípios, distribuídos em oito regiōes de governo: Metropolitana, Noroeste Fluminense, Norte Fluminense, Serrana, Baixadas Litorâneas, Médio Paraíba, Centro-Sul Fluminense e Costa Verde.

O território fluminense sempre exerceu forte influência no cenário econômico, político e social do Brasil, influência essa centrada na Região Metropolitana e, em especial, na cidade do Rio de Janeiro. Com as transformaçóes em curso em seu cenário, provocadas pela crescente importância das regiōes do interior, cada vez mais o foco analítico sobre as condiçōes de crescimento do estado se desloca para as cidades de porte médio e para a interpretação dos municípios como agentes das políticas públicas (Marafon apud Piquet, 2010).

O debate contemporâneo em torno do desenvolvimento econômico do estado de segundo maior Produto Interno Bruto (PIB) do país se encontra centrado nos investimentos em transporte e logística, com grandes empreendimentos, como o Complexo Portuário do Açu (São João da Barra), a Linha 4 do metrô carioca e o sistema de Transporte Rápido por Ônibus (BRT), além do Arco Metropolitano que liga o Porto de Itaguaí ao Complexo Petroquímico do Rio de Janeiro (Comperj), também localizado no município de Itaboraí. Esses empreendimentos reforçam a importância logística do Rio de Janeiro nacional e internacionalmente.

$\mathrm{O}$ interior fluminense, notadamente, surgiu como protagonista de um processo de crescimento em força, com exemplos de impacto: os das atividades da indústria petrolífera; o crescimento urbano nas Baixadas Litorâneas; o desenvolvimento da indústria automobilística no Centro-Sul do estado e;

\footnotetext{
1 Prof. Msc. em Geografia pela Universidade do Estado do Rio de Janeiro (UERJ).
} 
também no Norte Fluminense, a implantação do Complexo Logístico e Industrial do Porto do Açu (Clipa), que é um empreendimento porto-indústria, o foco deste trabalho.

Assim, este artigo analisa a construção de um porto privado no município de São João da Barra, litoral norte do estado do Rio de Janeiro: o Porto do Açu. Este trabalho está inserido nas pesquisas do Núcleo de Estudos de Geografia Fluminense (Negef), que estuda as importantes transformações acerca da realidade socioespacial do estado do Rio de Janeiro. Sobre a temática, segundo Alvarenga (2013, p. 3), os abundantes investimentos, as grandes promessas de desenvolvimento e o clamor de urgência de crescimento econômico acabaram por ser usados como armas para a legitimação de tudo o que pudesse estar associado a "progresso". Segundo o autor, também não foram poucas as vezes em que houve açôes que poderiam ser consideradas desrespeitosas no que diz respeito aos direitos das comunidades que viviam nas áreas do $5^{\circ}$ Distrito de São João da Barra, que foram desapropriadas pelo governo do estado do Rio de Janeiro para a construção do Distrito Industrial de São João da Barra (DISJB).

Os grandes projetos continuam a ser portadores de alto potencial de organização e transformação dos territórios, bem como de decompor e compor regiões. Por sua natureza, projetam sobre os espaços locais e regionais interesses nacionais e quase sempre globais, o que faz deles eventos globais-locais (Vainer, 2007).

É certo que a implantação de um megaempreendimento provoca metamorfoses rápidas e radicais na organização do território, acarretando aumento das desigualdades entre campo-cidade, bem como mudança na hierarquia urbana regional e no plano intraurbano. O aparecimento de áreas residenciais e de consumo de alto padrão social, ao lado da expansão dos bolsões de pobreza urbana, marca o descompasso entre os espaços dos trabalhadores inseridos no empreendimento - o que lhes garante emprego assalariado, renda acima da média, equipamentos e serviços urbanos de qualidade - e os espaços das populações que nele não conseguem ocupação. Como esses empreendimentos são tidos como capazes de desencadear "desenvolvimento", transformam-se em objeto de disputa entre regiōes e/ou municípios e, desse modo, no lugar da adoção de parâmetros quanto ao seu funcionamento, o que, em geral, ocorre são concessões do poder público, enfraquecendo ainda mais os cofres municipais (Marafon apud Piquet, 2010).

Assim, por não surgirem do processo de desenvolvimento regional, não expressam as forças políticas, sociais e econômicas endógenas. Nesse sentido, para Piquet (apud Marafon, 2010), tendem romper as relações econômicas e sociais que conformam antigas regionalizações, substituindo-as por outras construídas a partir deles. Segundo a autora, por ocorrer uma ligação das atividades-chave da economia do país e/ou internacional, seus administradores reportam-se diretamente às instâncias supralocais, deslocando para um plano subalterno as instâncias locais, que tendem a perder o controle político e administrativo. As pequenas e médias municipalidades e os próprios governos estaduais têm limitada capacidade de barganha, pois são parceiros de pequena monta frente aos grupos empresariais que manejam esses grandes projetos de investimentos.

O caso em análise não foge a esses condicionantes, e os efeitos não se limitam e/ou limitarão ao município de São João da Barra. A título de exemplo, no território sanjoanense o rápido processo de licenciamento ambiental para a instalação das diferentes unidades que deveriam compor o Clipa, bem como a disponibilização de forças policiais para cumprir os mandados de desapropriação de terras, 
foram possibilitados pela promulgação de quatro decretos pelo governo do Rio de Janeiro, no sentido de viabilizar a construção do DISJB e do denominado Corredor Logístico do Açu (CLA).

Em função da combinação de flexibilização da legislação com uso de força policial contra centenas de famílias de agricultores familiares, houve um inevitável aumento de tensões e conflitos, que passaram a inspirar uma série de questionamentos sobre qual modelo de desenvolvimento o Clipa representa e quais consequências sua construção pode gerar para as comunidades por ele impactadas. Nesse contexto, o Porto do Açu, além de ser um agente da reestruturação espacial, é responsável pela reorganização territorial do município de São João da Barra. As perspectivas de uma explosão demográfica acarretarão um irreversível processo de expansão urbana (Carvalho et al., 2010).

A metodologia adotada neste trabalho apresenta níveis exploratório e descritivo.

Enquadra-se no nível exploratório porque visa proporcionar maior familiaridade com o problema proposto, por meio do aprimoramento de ideias e descoberta de intuiçôes, apresentando um planejamento bastante flexível, de modo a possibilitar que diversos aspectos relativos ao fato proposto sejam levados em consideração.

É descritiva porque envolve a descriçāo das características de um fenômeno em processo de construção, recorrendo à coleta de dados e ao trabalho de campo, bem como relacionando as diversas variáveis identificadas. Ainda de acordo com Gil (2002, p. 10), "as pesquisas descritivas são, juntamente com as exploratórias, as que habitualmente realizam os pesquisadores sociais preocupados com a atuação prática".

O objetivo central que norteia este estudo é verificar como, na prática, se desdobra a relação entre o discurso oficial em torno desse megaempreendimento - que o apresenta como solução para os problemas de estagnação econômica da região Norte Fluminense - e a execução dos mecanismos de desapropriação e reassentamento utilizados pelo governo do estado do Rio de Janeiro.

Diante dessas expectativas e da metamorfose territorial ocorrida em São João da Barra, formulam-se as seguintes questôes: como controlar o comportamento de uma grandiosa corporação com altíssimo poder econômico? O que levou São João da Barra a ser escolhido para locação desse empreendimento? Os mecanismos adotados pelo Estado para reparar o impacto sobre a população que, tradicionalmente, habita o $5^{\circ}$ Distrito de São João da Barra levam em conta o ponto de vista e a necessidade dos atingidos?

\section{0 território de São João da Barra: passado e presente no contexto do Norte Fluminense}

São João da Barra é um município localizado na Região Norte do estado do Rio de Janeiro (Figura 1). Tem uma área de 455,04 km² e uma população de 32.747 habitantes, segundo dados do Censo 2010 (IBGE, 2010). Suas principais atividades econômicas são: turismo, agropecuária, olericultura, fruticultura ativa, artesanato e pesca, porém boa parte da arrecadação municipal provém do repasse de royalties do petróleo (Souza, 2010). 
Figura 1. Cartograma com a localização do município de São João da Barra-RJ

\section{REGIÃO NORTE FLUMINENSE}

MUNGCIPIOS

\section{IS}

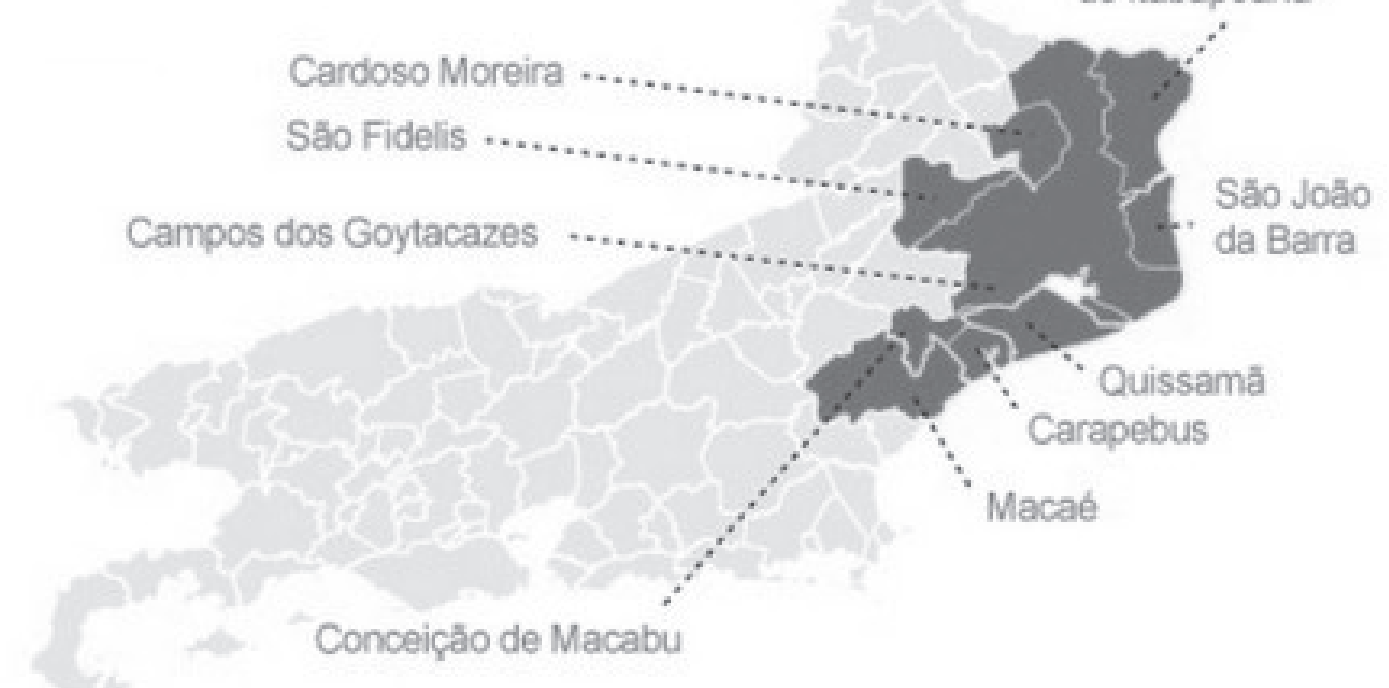

Fonte: Elaborado pelo autor.

Implantado pela holding EBX (do grupo de Eike Batista), o Complexo Logístico Industrial do Porto do Açu (Clipa) é considerado um porto concentrador de cargas, tendo sido projetado dentro da nova tipologia portuária denominada MIDAs (Maritime Industrial Development Areas), pois, na área contígua ao porto, estará um distrito industrial. Quando o complexo portuário foi divulgado, visava construir um terminal portuário de uso misto, composto por berços de atracação de navios, embarcações de apoio à exploração de petróleo e píer off-shore.

No distrito industrial, há previsão para a instalação de um complexo siderúrgico, usina termelétrica, polo metalmecânico, plantas de pelotização de minério, áreas para armazenamento de granéis líquidos e processamento de petróleo, além de uma unidade de construção naval (Coutinho, 2009).

O estudo dessa temática se justifica pela polêmica instaurada com o início da construção do Complexo Logístico Industrial do Porto do Açu (Clipa) no município de São João da Barra/RJ, desde o seu processo de licenciamento. Outrora marcada pela agroindústria açucareira, o território sanjoanense viu-se diante de uma nova oportunidade para alavancar seu crescimento. Assim, embasado nas mudanças mundiais, no surgimento de novas demandas por commodities e na favorável conjuntura político-econômica nacional, o governo do estado do Rio de Janeiro realizou os investimentos necessários para viabilizar o porto no Açu. Os entes privados (as empresas) e os públicos (o governo local e estadual) agiram juntos e de forma coesa para a implantação desse empreendimento. 


\section{Porto do Açu, entre as forças de conservação e modernidade}

Atualmente, a construção do complexo exerce forte pressão sobre os serviços ambientais e a população local, provocando modificação e impacto significativo no entorno. Compreender as expectativas dos agentes locais nesse contexto requer o devido acompanhamento a ser realizado pelos pesquisadores, o que justifica a presente pesquisa.

A história mundial comprova que os portos são elementos cruciais para o sistema econômico-comercial das nações, e seu desenvolvimento está intimamente ligado ao próprio desenvolvimento humano, sendo seus efeitos multiplicadores disseminados por todos os demais setores da economia (Santana Neto, 2005). As últimas décadas do século XX e o início do presente século foram marcados por profundas mudanças no processo produtivo. O processo de globalização traz consigo novas exigências logísticas e organizacionais, razão pela qual também a atividade portuária adquire nova importância no cenário global. E, no que diz respeito ao Complexo Logístico e Industrial do Porto do Açu, quais são os impactos positivos e negativos decorrentes dessa implantação portuária?

Barra do Açu, Vila do Açu ou, simplesmente, Açu já sofre grande pressão devido à proximidade com as atividades diretas do Clipa, e está geograficamente inserida em um território conflituoso, entre a zona industrial, a zona rural e a zona de proteção ambiental. Com aproximadamente 1.500 habitantes, localiza-se no litoral do município de São João da Barra e está a aproximadamente cinquenta quilômetros da sede de Campos dos Goytacazes.

Nosso foco de estudo é a influência do Porto do Açu nas metamorfoses ocorridas no uso da terra, bem como as mudanças territoriais havidas no município de São João da Barra. Discutem-se as peculiaridades do modelo de desenvolvimento ensejado pela instalação do Clipa em relação às suas consequências para as populaçôes que mais recebem seus ônus, ressaltando-se a relação entre os diferentes interesses envolvidos em sua construção e os indivíduos e comunidades que foram desalojados.

Não há como escapar da discussão sobre as relações de poder no território sanjoanense. No entanto, diante dos fortes encadeamentos que os investimentos previstos provocarão em São João da Barra e na Região Norte Fluminense em geral, levando a um elevado número de empregos diretos e indiretos e de receitas aos cofres públicos, o local tem muito a ganhar.

O município de São João da Barra está inserido numa região caracterizada por uma economia pauperizada, resultante de sua base de economia agropecuária pouco produtiva e de uma indústria agroaçucareira em crise constante. Recentemente, tornou-se dependente do repasse dos royalties do petróleo, que chegaram a contribuir com mais de $50 \%$ de toda a receita do município. Até os anos 1970, no Norte Fluminense predominava a agroindústria do açúcar. Com a criação do Programa Nacional do Álcool (Proálcool) - política adotada pelo governo brasileiro para fazer frente à alta brusca dos preços internacionais do petróleo em 1973, conhecida como primeiro choque do petróleo -, essa região perdeu a posição de grande produtora, por não acompanhar as mudanças tecnológicas modernizadoras nacionalmente adotadas pelos principais empresários do setor.

Nesse período, graças aos generosos financiamentos concedidos pelo governo federal, o parque industrial do setor de açúcar e álcool foi quase totalmente modernizado e reestruturado, passando uma boa parte das usinas do Norte Fluminense para as mãos de empresários externos à região, mais interessados na aquisição das cotas de produção dessas usinas que em suas instalações industriais - a maioria, inclusive, já ultrapassada do ponto de vista tecnológico. Uma vez que o setor era regulado pelo Estado nacional, a entrada de novos produtores estava sob seu controle, e cada indústria podia produzir apenas dentro dos limites de 
sua cota estabelecida. Os empresários paulistas, desejosos de ampliar a própria produção, passaram a adotar a estratégia de adquirir cotas de outras empresas para, em seguida, fechá-las e levar o "direito de produzir" para suas usinas. Nesse contexto, a Região Norte Fluminense, vista, desde o século XVII, como grande produtora de açúcar e álcool, foi deslocada de forma gradual porém inexorável do setor.

Esse Norte Fluminense histórico, que tem a cidade de Campos dos Goytacazes como principal polo, passou a apresentar problemas que iam de estagnação e queda dos índices de produtividade de seu principal produto a um elevado nível de desemprego, o que, consequentemente, levou a um processo de pauperização, desenraizamento e deslocamento do trabalhador rural para a periferia das cidades da região. No entanto, nesse momento, a Petrobras, que, desde a década de 1960, vinha desenvolvendo pesquisas na plataforma continental marítima, finalmente viu um de seus esforços resultar em sucesso: em 1974, o poço pioneiro 1-RJS-9A, situado a uma profundidade de cem metros, passou a produzir em vazão comercial e a se constituir em ponto de descobrimento de petróleo na Bacia de Campos (Caetano Filho, 2003, p. 52). Segundo Caetano Filho (2003, p. 47), o procedimento de se nomear uma bacia com o nome de uma cidade próxima ou acidente geográfico é internacionalmente regido pelo Código de Nomenclatura Estratigráfica.

Nesse contexto, a Bacia de Campos recebeu essa denominação em função de as descobertas marítimas terem ocorrido no litoral norte do estado do Rio, cuja principal cidade é Campos dos Goytacazes. A área estratigráfica dessa bacia tem cerca de $100.000 \mathrm{~km}^{2}$, estendendo-se do Espírito Santo até Cabo Frio. É necessário assinalar que a notícia da descoberta de petróleo na Bacia de Campos em um momento de plena crise mundial do petróleo, no auge do regime ditatorial brasileiro, parecia anunciar um novo tempo para a região.

O início da produção petrolífera colocava na ordem do dia a montagem de uma base operacional da Petrobras naquela área, e todos esperavam que isso ocorresse na cidade de Campos. No entanto, em 1978, a Petrobras, por questões logísticas, elegeu a cidade de Macaé, $100 \mathrm{~km}$ mais próxima da capital do estado, como sua base de atividades de prospecção e de produção. Inaugurou-se, então, um novo período econômico regional, dessa vez baseado, direta e indiretamente, nos recursos oriundos da exploração petrolífera. A elite açucareira, que, anos antes, propugnava as políticas para a região em nome dos próprios interesses, assistiu ao declínio de seu prestígio.

Ao longo dos anos, confirmou-se que as maiores reservas brasileiras de petróleo e gás se encontravam nessa bacia, que se tornou a produtora de cerca de $80 \%$ do petróleo e $40 \%$ do gás produzidos no país. Desde então, a Região Norte Fluminense passou por mudanças positivas no volume do PIB, na morfologia do tecido empresarial, na oferta de postos de trabalho, na demografia - com a chegada de trabalhadores qualificados e também de pessoas que buscavam alguma oportunidade -, na infraestrutura urbana, na educação e na saúde, e, principalmente, no aumento dos orçamentos municipais, em função dos generosos repasses garantidos pelo petróleo.

Tratando-se de uma aglomeração industrial baseada na extração de um bem natural não renovável, as empresas estão ali localizadas para explorar os recursos da região. Como as províncias de petróleo e gás apresentam um ciclo de vida - nascimento, crescimento, maturidade e declínio -, quando ambos os produtos se exaurem, as empresas líderes do setor dirigem-se para áreas com perspectivas de novas jazidas. Em situações tais, às empresas de pequeno e médio portes, fornecedoras de produtos ou serviços de alta competência tecnológica, resta a alternativa de se tornarem fornecedoras globais para a 


\section{Porto do Açu, entre as forças de conservação e modernidade}

indústria de petróleo, associando-se a grandes companhias multinacionais em novas províncias minerais. No entanto, para aquelas que atuam nos setores não intensivos, resta-lhes encerrar as atividades ou migrar para uma indústria correlata. Por essas razõse, foram frequentes os debates acerca do futuro econômico da região na era "pós-petróleo". Quis o destino que outras perspectivas surgissem no setor petrolífero: novas reservas de óleo e gás foram descobertas na camada de pré-sal e, em 2007, teve início a obra do Complexo Logístico-Industrial do Porto do Açu, no município de São João da Barra.

\section{Entendendo a economia e o processo de instalação do Porto do Açu}

No início dos anos 2000, mais precisamente a partir de 2003, após décadas de estagnação econômica, o Brasil deu início a um processo de retomada do crescimento, baseado numa mudança da conjuntura econômica mundial em que a China e os chamados Tigres Asiáticos (Coreia do Sul, Hong Kong, Singapura e Taiwan) passaram a ser grandes consumidores de commodities como minério de ferro, soja e insumos agrícolas. Ao mesmo tempo que a economia dos países do hemisfério Norte começava a apresentar traços de estagnação, que culminaram com a crise do sistema financeiro americano em 2008, o Brasil e os demais BRICS (abreviatura para o grupo de países composto por Brasil, Rússia, Índia, China e África do Sul) alavancaram um novo ciclo de crescimento da economia e das exportações.

No âmbito das políticas internas, o Brasil adotou políticas keynesianas como forma de distribuição de riqueza e justiça social, apostando na exportação de commodities a fim de manter o superávit da balança comercial. Pessanha et al. (2013) exemplificam a decisão de retomar os investimentos com o Porto de Suape, em Pernambuco, e com programas sociais como o Bolsa Família. Tais exemplos são uma nítida intenção de prover o país de uma nova e diversificada base de desenvolvimento, melhorando a renda das camadas mais pobres da população.

O processo de retomada econômica, contudo, trouxe à tona conhecidos problemas de infraestrutura, como os gargalos no sistema logístico-portuário nacional, típicos dos ciclos de crescimento da economia brasileira que ocorrem desde a segunda metade do século XIX, em que a infraestrutura só é reorganizada e ampliada após seu colapso. Nessa conjuntura de aumento das exportações de commodities e da necessidade de se contruírem novos terminais portuários, tem início a construção do Clipa no município de São João da Barra.

Em 1999, a Secretaria Estadual de Energia, Indústria Naval e Petróleo começou os estudos para a construção de um terminal portuário e de apoio offshore para a Petrobras no Norte Fluminense, junto à Bacia de Campos. Segundo Victer (2010), a ideia inicial de um porto estruturado para os granéis líquidos e de apoio offshore foi aperfeiçoada para também agregar a movimentação de granéis sólidos e contêineres. Após a realização de estudos de batimetria no litoral Norte Fluminense, chegou-se à conclusão que a região do Açu apresentava grande potencial para a viabilização desse empreendimento, sendo necessária apenas a construção de um extenso píer em direção ao oceano, aproveitando o elevado calado para a movimentação de grandes navios.

Com a escolha do local, o então governador, Anthony Garotinho, assinou o Decreto no 25.455, de 28 de junho de 1999, declarando, como de utilidade pública, para fins de desapropriação, quatro 
áreas desmembradas do imóvel rural denominado Fazenda Saco D’Antas, em São João da Barra. Victer (2010) ainda registra a aprovação de uma lei que delegava ao estado do Rio de Janeiro o investimento de $33 \%$ do valor do projeto, como forma de alavancar a construção do porto.

Em $1^{\circ}$ de setembro de 2000, em reunião pública realizada na Associação Comercial e Industrial de Campos (ACIC), foram divulgados os resultados dos primeiros estudos técnicos de engenharia, que apontavam a viabilidade de se construir o porto no Açu. Os relatórios, que custaram US\$ 500 mil ao governo estadual, também confirmaram a localização do terminal portuário em frente à Fazenda Saco D’Antas, conforme previsto no decreto de 1999 (Pessanha et al., 2013).

No entanto, mesmo com os investimentos iniciais prometidos, o projeto do porto não foi aceito pela Petrobras nem pelas empresas da iniciativa privada que se haviam mostrado interessadas. Desse momento em diante, já no ano de 2004, houve o redirecionamento do projeto para o setor de granéis sólidos, em especial o minério de ferro. As negociações, então, foram feitas com a Vale, que também não se mostrou interessada no projeto (Victer, 2010). Assim, após as recusas pela Petrobras e pela Vale, o então secretário de Energia, Petróleo e Indústria Naval, Wagner Victer, autorizado pela governadora Rosinha Garotinho, entregou o projeto ao empresário Eike Batista. Essa transferência do projeto para um novo investidor contou com a interferência de Eliezer Batista, ex-presidente da Companhia Vale do Rio Doce, pai do empresário Eike Batista e também membro do Conselho de Desenvolvimento Econômico e Social do Rio de Janeiro (CDES-RJ), órgão consultivo que acompanhou, desde o início, os estudos de implantação do porto.

Assim, em 27 de dezembro de 2006, foi colocada a pedra fundamental para a construção do porto, embora, efetivamente, as obras só tenham iniciado em março de 2007 (Pessanha et al., 2013). A partir de então, sob a coordenação do Grupo EBX, o projeto do porto passou por uma nova reformulação, adequando-se à nova realidade de se agregarem atividades industriais a atividades portuárias. Essa nova concepção, denominada MIDAs (Maritime Industrial Development Areas), encontrou no Porto do Açu o ambiente ideal para sua implantação. No entanto, sabe-se que, dentro das estruturas portuárias do tipo MIDAs, são necessárias extensas retroáreas para a construção dos distritos industriais e dos terminais de contêineres, algo quase impossível de se encontrar no litoral sudeste brasileiro. Diante disso, Quinto Jr. et al. (2011) ressaltam outro aspecto importante na escolha do município de São João da Barra para a instalação do complexo portuário industrial: a questão fundiária.

\section{As transformações no uso da terra: mudanças territoriais em São João da Barra}

Fernandes (2008) argumenta que o ponto de partida para a análise do território consiste em se compreender o que é espaço, local onde a vida humana se materializa.

No espaço, natureza e sociedade estariam unidos de forma indissociável, pois as relações sociais no espaço transformam a natureza, e esse mesmo espaço é transformador das relaçôes sociais. Nesse movimento cíclico e ininterrupto é que se formam os territórios, ou seja, o território é construído a partir do espaço, pois, diante da necessidade de garantir sua existência, os homens fragmentam o espaço e criam seus territórios. 


\section{Porto do Açu, entre as forças de conservação e modernidade}

Fernandes propõe a criação de duas categorias para distinguir os territórios: materiais e imateriais, em que os primeiros dizem respeito aos territórios formados no espaço físico, enquanto os segundos são formados no espaço social. Essas duas categorias seriam indissociáveis e dependentes, uma vez que o território formado no espaço físico deveria ser sustentado pelo território material em forma de conhecimento, ideologia e teoria. De forma análoga, Corrêa (1998) argumenta que o território está submetido à organização espacial, ou seja, ao espaço. O território, portanto, seria o espaço revestido de dimensão política e/ou afetiva. Corrêa também sugere que é na ação dos agentes sociais (por exemplo, Estado, grupos sociais e corporações econômicas), com vistas à garantia da apropriação e da permanência em dado território, que se constitui a territorialidade.

Para Fernandes e Corrêa, o território seria, portanto, uma totalidade e, dentro dessa totalidade, estariam as dimensões política, social, natural, cultural e econômica. Assim, cada sujeito ou grupo, ao se apropriar do espaço, construiria seu território, decidindo explorar uma ou mais de suas dimensões, e, assim, outro grupo que também se apropriasse desse mesmo espaço poderia explorar as dimensões de seu próprio interesse. Assim, as ações tomadas que levam em conta o território como espaço de governança teriam de considerar esse território propriedade individual e vice-versa (Fernandes, 2008; Corrêa, 1998). Por outro lado, Haesbaert (2005) chama a atenção para o caráter duplo do território, que, como já vimos, seria composto pelas dimensôes simbólica e material, ambas ligadas à busca pelo poder. A primeira delas seria a apropriação e a dominação da terra, e a segunda, uma consequência desta, a inspiração de terror sobre os que foram dominados, vendo-se forçados a abandonar dado território ou impedidos de entrar e/ou permanecer nele.

Em todas as proposições apresentadas, fica clara a importância do conflito na construção e desconstrução do território. Fernandes (2008), por exemplo, é categórico ao considerar a conflitualidade como parte integrante do processo de formação e desenvolvimento da disputa territorial. Haesbaert (2005), por sua vez, sugere que a busca por influenciar pessoas, fenômenos e relacionamentos é o que mobiliza a tentativa de controle do espaço. Assim, para Haesbaert, a territorialidade não se restringe ao domínio de um lugar físico e à sua dimensão política; ela também representa a capacidade de, através desse lugar, experimentar o mundo e produzir significados, envolvendo, portanto, as dimensões cultural e econômica.

Assim, a disputa permanente seria parte integrante do território, que se deve, principalmente, à impossibilidade de realização de uma classe ou grupo social em um território que já esteja sob o controle de outrem. As diferentes e até mesmo divergentes formas de organização, relações sociais, planos de desenvolvimento e finalidades de cada classe para o território impossibilitariam tal realização. Essas diferentes formas de se apropriar, simbólica e materialmente, do ambiente, as quais revelam diversos modos de produção de seu espaço, são o que Laschefski (2011) caracteriza como territorialidade.

De forma semelhante, para Neves (1988), a territorialidade seria dada pelo conjunto formado por ação e poder dentro do espaço. Nessa perspectiva, o poder é entendido como a capacidade de decidir, a qual pode ser exercida sobre os lugares quando se é adaptável a circunstâncias espaçotemporais contraditórias. Neves também postula que a eficácia e a amplitude desse poder são definidas pela densidade dos fragmentos e pelas obstrução e construção de canais das múltiplas redes vinculadas às condiçōes históricas dadas.

Nesse contexto, as redes são construídas ou desconstruídas sempre por ações políticas, numa disputa entre os locais, mesmo que apresentadas como lutas a favor da democracia e contrárias à opressão. 
Essas lutas também são travadas pela construção do território, uma vez que o que está em jogo é a soberania sobre o espaço. Assim, o exercício de poder sobre o espaço é o que o transforma em território. Não se trata, contudo, apenas do poder como dimensão econômica; trata-se também do poder exercido pela força cultural do grupo, capaz de unificar os fragmentos de um território (Neves, 1988).

Além disso, Corrêa (1988) ressalta que, embora esteja relacionado à ligação de um grupo ao espaço, um mesmo espaço pode apresentar diferentes territorialidades, visto que pode ser apropriado e vivenciado de modo diverso pelos diferentes grupos. Em suma, em um mesmo espaço, haveria vários territórios com múltiplas possibilidades de arranjo. Entretanto, quando há perda desse território apropriado e vivido, o que ocorre, segundo Corrêa, seria a desterritorialidade, fomentada pelas contradições capazes de desfazer um território. A desterritorialidade, por sua vez, pode não ser seguida pela desterritorialização, que viria a ser o deslocamento espacial dos grupos derrotados de seus territórios.

A partir dessas diferentes formulações sobre território, desterritorialidade e desterritorialização, Fernandes (2008) aponta a necessidade de se pensar em políticas territoriais que levem em conta a multiescalaridade e a multidimensionalidade do território. No entanto, contra essa sugestão pesa o fato de a prática comum entender o território como um espaço de governança, anulando seus atributos e considerando-o uma entidade única. $\mathrm{O}$ fato é que, quando as múltiplas dimensões e a totalidade do território são reduzidas, determinado território tem de ser privilegiado para se aplicarem políticas de desenvolvimento.

Assim, considerando as diferentes disputas e relações de poder existentes em dada sociedade, os grupos de maior poder político são os privilegiados. Essa opção está em sintonia com os interesses de reprodução capitalista e com o processo de dominação pretendido pelas classes dominantes. Essa exploração-dominação é ainda pior quando se verifica o uso de um discurso que, contraditoriamente, defende formas de empoderamento a esses grupos socialmente marginalizados quando, na realidade, o que ocorre é o fortalecimento dos interesses das classes detentoras de capital. Por fim, Haesbaert (2005) afirma que, devido à hegemonia da lógica capitalista, a reapropriação é inibida, pois o espaço é considerado único, sendo fadado, portanto, ao domínio pelo aparato empresarial e pelo Estado.

De 2007 a 2014, da construção até a atualidade, o Complexo Logístico e Industrial do Porto do Açu passou por muitas mudanças, com o Grupo EBX, do empresário Eike Batista, investindo, de forma significativa, nesse empreendimento. Anos mais tarde, foi necessário reestruturar o Grupo EBX, em função da falência da OGX, que acabou repercutindo nas outras empresas da holding e na diminuição do valor das commodities no mercado internacional, provocando uma nova reestruturação no projeto.

\subsection{Complexo Logístico e Industrial do Açu: uma nova territorialidade produtiva na Região Norte Fluminense (2007-2014)}

Cobrindo uma área de $90 \mathrm{~km}^{2}$ e localizado estrategicamente no norte do estado do Rio de Janeiro, o Porto do Açu está a cerca de $150 \mathrm{~km}$ da Bacia de Campos, onde quase 80\% do petróleo brasileiro é produzido. Sua construção teve início em outubro de 2007. Atualmente em operação, o porto conta com $17 \mathrm{~km}$ de cais e até $23 \mathrm{~m}$ de profundidade, com capacidade para receber até 47 
embarcações simultaneamente, incluindo navios de grande porte, como Capesize e Very Large Crude Carrier (VLCCs), que transportam até 320 mil toneladas de carga.

Segundo os conceitos mais modernos de porto-indústria, o Porto do Açu contará com um distrito industrial e uma retroárea para armazenamento e movimentação de carga. Essas áreas, em conjunto com o porto, formarão o Complexo Industrial do Porto do Açu, onde serão instaladas indústrias offshore, polo metalmecânico, base de estocagem para granéis líquidos, estaleiros, base para tratamento de petróleo, termelétricas, pátio logístico, terminal de reparo naval, entre outros.

O Porto do Açu foi idealizado para fazer parte de uma gama de projetos interligados e mutuamente viabilizados, e será o maior empreendimento desse conjunto, pois tem a responsabilidade de atrair as principais empresas para São João da Barra, além de viabilizar a exportação do minério extraído pela MMX Minas-Rio Mineração, em parceria com a Anglo Ferrous Minas-Rio Mineração S.A, em Conceição do Mato Dentro/MG (Rima, 2010). O mineroduto é o projeto mais adiantado, iniciado em $2007 \mathrm{com}$ a construção de um píer para a ligação terminal de cargas ao continente (Figura 2). Essa construção já vem provocando impacto em uma das principais atividades econômicas da população local, a pesca.

Figura 2. Traçado do mineroduto Minas-Rio desde a serra (MG) até São João da Barra.

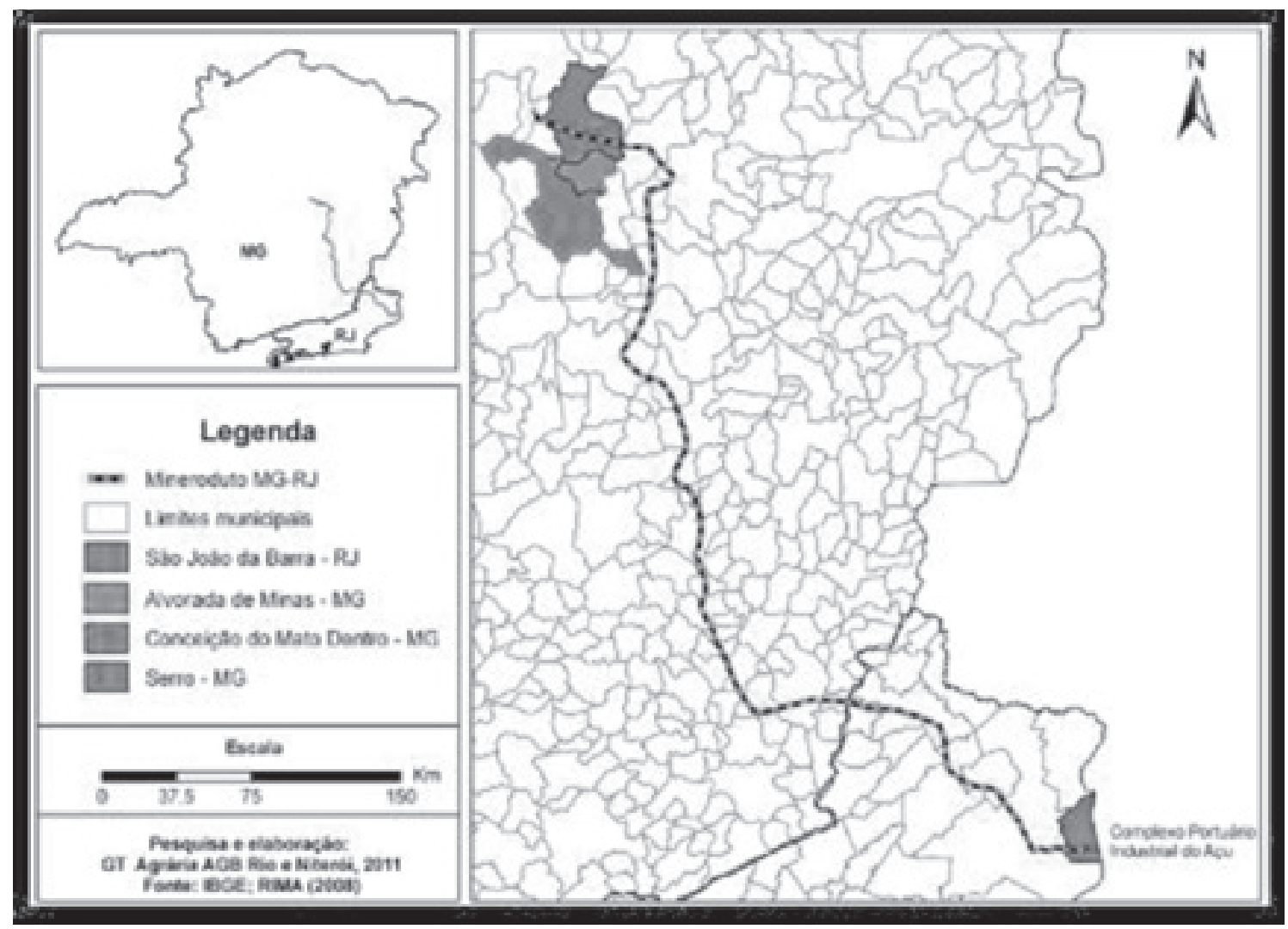

Fonte: AGB, 2011. 
O projeto do Clipa ainda prevê a construção de uma usina termelétrica no condomínio industrial na área de retaguarda do porto, que, pela facilidade de formação de energia elétrica e de saída para exportação, atrairá usinas siderúrgicas e montadoras para a área (AGB, 2011). Além dessas facilidades, o mineroduto levará minério de ferro do interior de Minas Gerais ao Norte Fluminense a baixo custo, por fazer seu beneficiamento no próprio porto, nas siderúrgicas ou nas unidades de pelotização, o que também poderá beneficiar as siderúrgicas, ao agregar valor ao produto e possibilitar maiores ganhos com a exportação de ligas de metal de baixo custo, e não do material bruto.

\subsection{A desterritorialização em São João da Barra}

Com a finalidade de construir o Distrito Industrial de São João da Barra (RJ), os decretos estaduais 42.584 e 41.585, de 05/12/2008, 41.915 e 41.916, de 19/06/2009, e 41.998, de 19/08/2009, desapropriaram, com fins de utilidade pública, a cargo da Companhia de Desenvolvimento Industrial do Estado do Rio de Janeiro (Codin), os imóveis destinados a abrigar o DISJB, numa área total de 7.200 hectares. Segundo dados apurados por pesquisadores da Associação de Geógrafos Brasileiros (AGB, 2011), a área desapropriada era ocupada, basicamente, por pequenos agricultores. Assim, como aponta Haesbaert, ocorreu uma desterritorialização. Durante o processo de audiência pública, promovido pelo Inea e pela Codin, questôes sobre a desapropriação das famílias e informaçôes sobre as garantias previstas no "reassentamento" teriam sido pautas ocultas e pouco esclarecedoras.

Nesse sentido, em parceria com empreendedores privados, a Codin desenvolveu um assentamento rural na área da antiga Fazenda Palacete, localizada no V Distrito de São João da Barra. Essa propriedade passou a ser chamada de Vila da Terra, com a finalidade de abrigar as famílias que atendessem a critérios estabelecidos pela Codin, conforme resultado do cadastro socioeconômico realizado na região. Assim, entre os critérios estabelecidos pela Codin para participação no reassentamento, estavam: 1) Ser proprietário/posseiro e residente no imóvel rural contido no polígono decretado de utilidade pública, com propriedade inferior a 10 ha: 2) Pertencer a famílias em condição de hipossuficiência social atingidas pela implantação do Distrito Industrial de São João da Barra: 3) Ter sido cadastrado na pesquisa socioeconômica aplicada em 2009, atualizada entre janeiro e março de 2011.

Desse modo, construída a partir de uma parceria entre a Codin, a Prefeitura Municipal de São João da Barra e a LLX, a Vila da Terra foi planejada para alocar cerca de noventa famílias numa área que, além das casas, contaria com uma quadra poliesportiva e um centro comercial. A Vila da Terra tem sido apresentada como um modelo inédito de reassentamento rural e, vendida como dentro dos padróes estabelecidos pelo Banco Mundial, referência internacional em reassentamento, contará com cerca de mil hectares.

Segundo informações divulgadas no site e em vídeos promocionais do empreendimento pelo Grupo EBX, na época inicial de implantação do porto, a Vila da Terra foi planejada com ruas pavimentadas, quadra poliesportiva, centro comunitário, iluminação pública, rede de água e esgoto e centro comercial. Os lotes, cujo tamanho variaria entre 2 e 10 ha, apresentariam três diferentes tipologias, com dois, três ou quatro quartos, e áreas de construção entre 68 e $109 \mathrm{~m}^{2}$. No caso dos produtores rurais que possuíssem residência anterior com área superior a $109 \mathrm{~m}^{2}$, a casa seria construída no tamanho da metragem original. Os proprietários com terrenos maiores que 10 ha receberiam os valores correspondentes à desapropriação. 


\section{Porto do Açu, entre as forças de conservação e modernidade}

Inaugurada em outubro de 2011, a Vila da Terra, no momento em que esta pesquisa foi realizada, abrigava vinte famílias, de acordo com dados dos próprios moradores, estando ainda prevista a transferência de um número indeterminado para aquele local, de acordo com o andamento do conturbado processo de desapropriação.

Analisando, em trabalho de campo, as características da Vila da Terra, foi possível perceber sua importância para esses moradores. Em primeiro lugar, por ser seu local de moradia e existência, uma vez que nasceram e constituíram suas famílias ali. Em segundo lugar, a importância daquele chão está no papel que desempenha como fornecedor dos meios de trabalho e condição de subsistência (agricultura).

Essa caracterização rural, marcada pela relação com a terra, chama a atenção para os impactos que a construção do Cipa está causando na região, uma vez que as rupturas com os espaços tradicionais que, historicamente, têm condicionado as formas sociais nas localidades, provocadas pela instalação de grandes empreendimentos, serão mais relevantes quanto mais as estratégias de trabalho e condiçôes de existência estiverem associadas ao meio biótico natural (Acserald e Silva, 2011).

\subsection{Porto do Açu no cenário atual}

Segundo Moreno (2014), em junho de 2012 teve início a queda do empresário Eike Batista e, em consequência, de muitos de seus projetos. No mesmo mês, a holding do empresário recebeu um comunicado de que a produção de petróleo da OGX Petróleo e Gás Ltda. (OGX) estava 50\% abaixo das previsões estimadas, o que prejudicou toda a avaliação da companhia por parte do mercado. Nesse contexto, os investidores passaram a ter um olhar cético sobre o grupo, pois os problemas iam se sucedendo e as empresas mudavam de acionistas ou entravam em recuperação judicial por causa das vultosas dívidas. Em setembro de 2013, a LLX Logística, que geria o porto do Açu, teve o controle acionário repassado para o Grupo EIG, após a assinatura de um contrato de investimentos no valor de $\mathrm{R} \$ 1,3$ bilhão. Em dezembro do mesmo ano, a LLX Logística passou a se chamar Prumo Logística Global.

Atualmente, a empresa mantém seus investimentos na construção do porto do Açu. Em 25 de outubro de 2014, realizou-se o primeiro carregamento de minério de ferro. Um total de 80 mil toneladas do produto foi embarcado para a China. O carregamento desse primeiro navio é um marco para a história do porto e da região, pois concretiza os investimentos e as especulaçóes ali realizados nos últimos 15 anos (1999 a 2014), tornando irreversíveis as mudanças em curso no entorno do Clipa.

A reestruturação do Grupo EBX, em função da falência da OGX, que acabou por repercutir nas outras empresas da holding, e a diminuição do valor das commodities no mercado internacional provocaram uma nova reestruturação do projeto. As indústrias siderúrgicas e cimenteiras foram abortadas, porém as empresas que estão se instalando no complexo retomam a concepção original desenhada no final da década de 1990, que era de um porto de apoio às atividades offshore na Bacia de Campos. Nesse contexto, as áreas destinadas à Codin e ao DISJB deverão ser ocupadas em longo prazo.

Quanto às famílias que passaram pela desapropriação, muitas ainda não receberam da empresa as respectivas indenizaçóes, gerando, no contexto atual, um grande conflito entre o porto e a população. As obras de implantação estão em andamento, com previsão de término para final de 2016. 
As forças conservadoras, que representam a população diretamente atingida pela instalação portuária, ainda lutam por seus direitos, enquanto as forças que defendem a modernidade, movidas pela globalização, seguem, sem pensar nas necessidades dos atingidos, mas tão somente no lucro a ser gerado para a empresa.

\section{Considerações finais}

$\mathrm{Na}$ construção do Porto do Açu, os principais atingidos são os pescadores e agricultores familiares, que estão passando por um período de insegurança e insatisfação, decorrente do processo de desapropriação de suas terras, que ignorou os mecanismos legais estabelecidos pela própria Constituição Estadual. A falta de obediência aos ditames legais por parte do governo do Rio de Janeiro nas desapropriações realizadas também se verificou na emissão das licenças ambientais relacionadas à instalação do Clipa.

Em outro sentido, levando-se em conta as condições que cercaram as desapropriações e a (falta de) negociação com as comunidades e os indivíduos atingidos, afirma-se que o Estado atuou como parceiro dos empreendedores privados, provendo investimentos diretos, melhora nas estradas de acesso e condições para seu pleno estabelecimento. No entanto, não se observou o mesmo tratamento em relação aos agricultores e pescadores. Esse tratamento desigual contribuiu para o surgimento de conflitos que, em última instância, conduziram a atrasos e pendências, com efeito negativo para a própria construção do Clipa.

Certamente, o Complexo Logístico do Açu pode ser relacionado a impactos socioambientais e à precarização das condições de trabalho e de reprodução social das comunidades que moravam no 5은 Distrito. Esse fato corrobora assertivas constantes na literatura de que o modelo neodesenvolvimentista se baseia no uso intensivo dos recursos naturais, ignorando uma avaliação mais profunda do respectivo impacto socioambiental e a falta de alternativa para aqueles que são política e economicamente marginalizados com sua adoção.

Para concluir, assinala-se que, no processo de implantação autoritária de megaempreendimentos, como no caso do Porto do Açu, o que se materializa é a disputa entre duas racionalidades em relação a qual modelo de desenvolvimento e progresso seria mais apropriado. Outro aspecto importante é a persistência da força que a ideologia do desenvolvimento possui até entre aqueles que mais têm a perder, na medida em que os atingidos não querem ser vistos como obstáculos ao progresso, embora sejam os principais prejudicados nas novas relações de poder estabelecidas em seus próprios territórios.

Os resultados desta pesquisa também colocam em xeque a noção de desenvolvimento como um mero processo de crescimento econômico. Esse processo, para ser alcançado em sua plenitude, requer a adoção de medidas que ampliem os mecanismos de participação nos processos decisórios, que sirvam para criar mecanismos de participação efetiva, de modo que os habitantes dos territórios que passam por transformação possam ser ouvidos, em vez de ser tratados como símbolos de formas sociais atrasadas. 
Porto do Açu, entre as forças de conservação e modernidade

\section{Referências}

ACSELRAD, Henri. “Território e poder: as políticas das escalas”. In FISHER, Tânia (org.). Gestão do desenvolvimento e poderes locais: marcos teóricos e avaliação. Salvador: Casa da Qualidade, 2002.

—_. "Rearticulações da terra e do trabalho em áreas de grandes projetos hidrelétricos na Amazônia". In ZHOURI, Andréa (org.). As tensōes do lugar: hidrelétricas, sujeitos e licenciamento ambiental. Belo Horizonte: Editora UFMG, 2011.

AGB. Relatório dos Impactos Socioambientais do Complexo Industrial Porto do Açu. S.1., 2011.

ALVARENGA, F. M. Os deserdados do desenvolvimento: o caso da implantação do Complexo Portuário e Industrial do Açu e seus impactos socioterritoriais (dissertação). UENF, 2013.

CAETANO FILHO, E. "O papel da pesquisa nacional na exploração petrolífera da margem continental na Bacia de Campos”. In PIQUET, R. (org.). Petróleo, royalties e região. Rio de Janeiro: Garamond, 2003, pp. 39-94.

CARVALHO, L. S. et al. "O Porto do Açu no contexto da reestruturação espacial”. Porto Alegre, Encontro Nacional dos Geógrafos, 2010.

CORRÊA, R. L. “Territorialidade e corporação: um exemplo”. In SANTOS, Milton et al. Território: globalização e fragmentação. 4 ed. São Paulo: Hucitec/Anpur, 1988.

COUTINHO, R. R. Avaliação das transformações socioambientais oriundas da implantação do Complexo Portuário Industrial do Açu (dissertação). IFF, 2009.

FERNANDES, B. M. "Entrando nos territórios do território". In PAULINO, Eliane Tomiasi e FABRINI, João Edmilson. Campesinato e territórios em disputa. São Paulo: Expressão Popular, 2008, pp. 273-302.

GIL, A. C. Como elaborar projetos de pesquisa. São Paulo: Atlas, 2002.

HAESBAERT, R. "Da desterritorialização à multiterritorialidade”. Anais... X Encontro de Geógrafos da América Latina. São Paulo, USP, 2005.

IBGE. Censo 2010. Rio de Janeiro, 2010.

LASCHEFSKI, K. "Licenciamento e equidade ambiental: as racionalidades distintas de apropriação do ambiente por grupos subalternos". In ZHOURI, Andréa (org.). As tensóes do lugar: hidrelétricas, sujeitos e licenciamento ambiental. Belo Horizonte: Editora UFMG, 2011.

MARAFON, G. J. e SANT'ANNA, M. J. G. (orgs.). Rio de Janeiro: um olhar socioespacial. Rio de Janeiro: Gramma, 2010.

NEVES, G. R. “Territorialidade, desterritorialidade, novas territorialidades (algumas notas)". In SANTOS, Milton et al. Território: globalização e fragmentação. 4 ed. São Paulo: Hucitec/Anpur, 1988

PIQUET, Rosélia e SERRA, Rodrigo (orgs.). Petróleo e regiāo no Brasil: o desafio da abundância. Rio de Janeiro: Garamond, 2007.

QUINTO JR, Luiz de Pinedo et al. Implantação de um Complexo Industrial Portuário: o caso do Porto do Açu. Agenda Social. Campos dos Goytacazes, 2011. 
SANTANA NETO, J. V. de. A lei 8.630/93 e a modernização portuária no Brasil: um estudo dos impactos da privatização da operação portuária na movimentação da carga conteinerizada no porto público organizado de Salvador (dissertação). UFBA, 2005.

SOUZA, T. N. de. Avaliação dos impactos causados pela implantação do Complexo Portuário do Açu sobre as atividades de pesca artesanal marinha na regiāo Norte Fluminense (dissertação). IFF, 2010.

VAINER, C. "Planejamento territorial e projeto nacional: os desafios da fragmentação". Revista Brasileira de Estudos Urbanos e Regionais, Anpur, 2007, v. 9, n. 1, pp. 9-24.

VICTER, Wagner. "Porto do Açu”. 2010. Disponível em: http://oglobo.globo.com/blogs/wagner/ posts/2010/04/14/porto-do-acu-283776.asp. Acesso em: 26 abr. 2016. 